\title{
Use of health services among international migrant children - a systematic review
}

Niina Markkula ${ }^{1 *} \mathbb{D}$, Baltica Cabieses ${ }^{1,2}$, Venla Lehti ${ }^{3}$, Eleonora Uphoff ${ }^{3}$, Sofia Astorga ${ }^{1}$ and Francisca Stutzin ${ }^{1,4}$

\begin{abstract}
Background: Migrant children have specific health needs, and may face difficulties in accessing health care, but not enough is known about their health service use. This study aims to describe patterns of use of health services of international migrant children and differences to respective native populations.

Methods: Electronic databases PubMed and Web of Science, references of identified publications, and websites of relevant international agencies were searched. We included observational studies published between 2006 and 2016 that reported use of formal health services by migrant children (0-18 years), including first and second generation migrants. Data on study characteristics, study theme, main outcome and study quality were extracted.

Results: One hundred seven full texts were included in the review. Of the studies that reported comparable outcomes, half (50\%) indicated less use of healthcare by migrants compared with non-migrants; $25 \%$ reported no difference, $18 \%$ reported greater use, and $7 \%$ did not report this outcome. There was variation by theme, so that the proportion of conclusions "less use" was most common in the categories "general access to care", "primary care" and "oral health", whereas in the use of emergency rooms or hospitalisations, the most common conclusion was "greater use".
\end{abstract}

Conclusions: Migrant children appear to use different types of healthcare services less than native populations, with the exception of emergency and hospital services.

Systematic review registration: PROSPERO systematic review registration number: CRD42016039876.

Keywords: Transients and migrants, Immigrants, Children, Health service use, Access

\section{Background}

International migration is a global concern and a wellknown social determinant of health [1,2]. Migration as a phenomenon has health impacts both at the individual and population level [3-5]. However, the recognition of migration as a social determinant of health is not straightforward, as this implies taking a moral stance regarding values of ethics and fairness in policy making [6]. There were 258 million international migrants in the world in 2017, 49\% more than in the year 2000 [7]. Migrants represent $3.4 \%$ of the world's population and $14 \%$ of the population living in high-income countries. One in ten migrants is a refugee [7]. In October 2016,

\footnotetext{
* Correspondence: niina.markkula@helsinki.fi

${ }^{1}$ Social Studies in Health Research Programme, Instituto de Ciencias e Innovación en Medicina (ICIM), Facultad de Medicina, Clínica Alemana Universidad del Desarrollo, Av. Las Condes 12461, Las Condes, Santiago, Chile

Full list of author information is available at the end of the article
}

the New York Declaration of the United Nations General Assembly urged all countries to protect the human rights of all refugees and migrants, placing special emphasis on vulnerable groups such as migrant children [8]. The health sector has been criticised for its slow response to the commitments of the assembly [9].

It has been estimated that 37 million international migrants are children, including 11 million refugees and asylum seekers [10]. In the past 10 years, the number of child refugees has more than doubled [10]. All children, including international migrants, have a human right of access to health care facilities that allow them to enjoy the highest attainable standard of health [11]. Refugee and asylum seeking children who may have had a dangerous journey and face adverse living conditions are particularly vulnerable [12]. International migrant children need specific attention and there is an opportunity for healthcare systems, amongst other social structures,

(C) The Author(s). 2018 Open Access This article is distributed under the terms of the Creative Commons Attribution 4.0 International License (http://creativecommons.org/licenses/by/4.0/), which permits unrestricted use, distribution, and 
to address the protection and recovery of their wellbeing and health throughout their life course [13].

International migrant children and youth face different health challenges compared with local populations due to the psychosocial stress of the migration process, adverse social conditions and increased exposure to health risks $[1,14,15]$. The available literature shows differences in health status of migrant children from the moment of birth: children born to mothers with immigrant background have a higher incidence of stillbirth, neonatal death, premature delivery and low birth weight $[16,17]$. Among young children, higher rates of dental cavities, some infectious diseases and obesity have been found $[17,18]$. Also higher rates of some mental disorders have been reported [19-21].

Systematic reviews on the use of health services among adult migrants have found varying patterns of health care use, so that the use of preventive services is lower than among the general population, but the use of primary care and rate of hospitalisations is higher [16, 22-24]. However, these findings cannot be generalized to children. In the case of children, the decision-making involves also their parents or other caretakers, and possibly other actors. Few available studies suggest that language barriers [25] and parents' expectations [15] are particularly relevant determinants of access to healthcare. Large differences have been found in health service use depending on the type of service and origin of the children, making it difficult to extract information to support health policy decision-making $[17,26]$.

With the increase in international migration [7], it seems relevant to collect and systematize pertinent information on health service use of migrant children. This systematic review aims to describe use of health services of international migrant children and possible differences to respective local populations in different healthcare settings.

\section{Methods \\ Type of study}

We conducted a systematic review in accordance with the guidelines set by the Preferred Reporting Items for Systematic Reviews and Meta-Analyses (PRISMA) statement. The study protocol was registered at PROSPERO in May 2016 (http://www.crd.york.ac.uk/PROSPERO/display_record.php?ID=CRD42016039876, registration No. CRD420 16039876).

\section{Search strategy}

We searched PubMed and Web of Science electronic databases using the search terms specified in Table 1, for publications published in January 2006 to May 2016. This timeframe was chosen because changes in patterns of migration may have influenced access in recent decades and the aim was to analyse the current situation,
Table 1 Search strategy

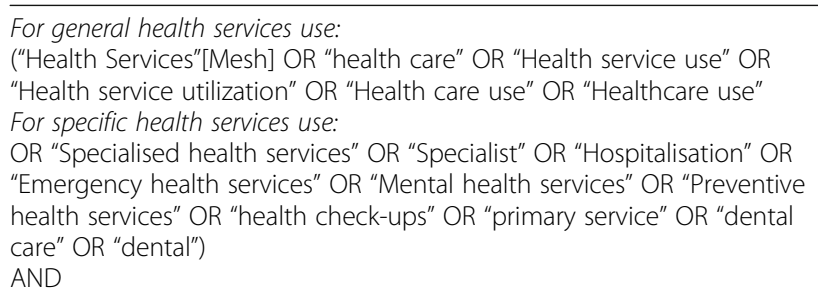

("Transients and Migrants"[Mesh] OR "Emigrants and immigrants"[Mesh] OR "Refugee" OR "Migration background" OR "Immigrant background" OR "Migrant" OR "Migrants" OR "Immigrant" OR "Immigrants" OR "Ethnic minority")

AND

("Child"[Mesh] OR "Children" OR "Adolescent" OR "Adolescents" OR "Youth" OR "minor")

AND

("cohort studies"[Mesh] OR "case-control studies"[mesh] OR "comparative study"[pt] OR "risk factors"[mesh] OR "cohort"[tw] OR "compared"[tw] OR "groups"[tw] OR "case control"[tw] OR "multivariate"[tw])

which was considered more useful to orient health policies. A filter for observational studies was used as detailed in Table 1. The database search was carried out in May 2016 (Fig. 1). The search in PubMed yielded 1912 hits and Web of Science 705 hits. Additionally, we searched the website of the International Office for Migration (IOM). This search yielded one additional publication.

\section{Inclusion and exclusion criteria}

Study inclusion criteria were 1) Study population included international migrant children and adolescents aged less than 18 years old. First and second-generation migrants were included. If the study reported a wider age range, studies were included only if they reported results separated for children; 2) The study methodology was quantitative and observational, including cross-sectional, casecontrol and cohort studies; 3) The study reported on health service use. Migrant was defined as someone who has (or in the case of second-generation migrants, whose parents have) crossed a national border to reside in another country for a year or longer. Publications referring only to ethnic minorities without clearly stating the migration status of the participants were not included. All formal health services were included, whether primary, secondary, preventive or curative, public or private. All types of contact with health services were included, and "health service use" was conceptualized to encompass concepts such as effective use and utilization, and also having a usual source of care [27]. Use of prescription medication was considered to indicate use of health services. Studies analysing national migration, only analysing health insurance status and economic evaluations were excluded. Studies in English, Spanish, Portuguese, French, Dutch, Swedish and Finnish were included. 


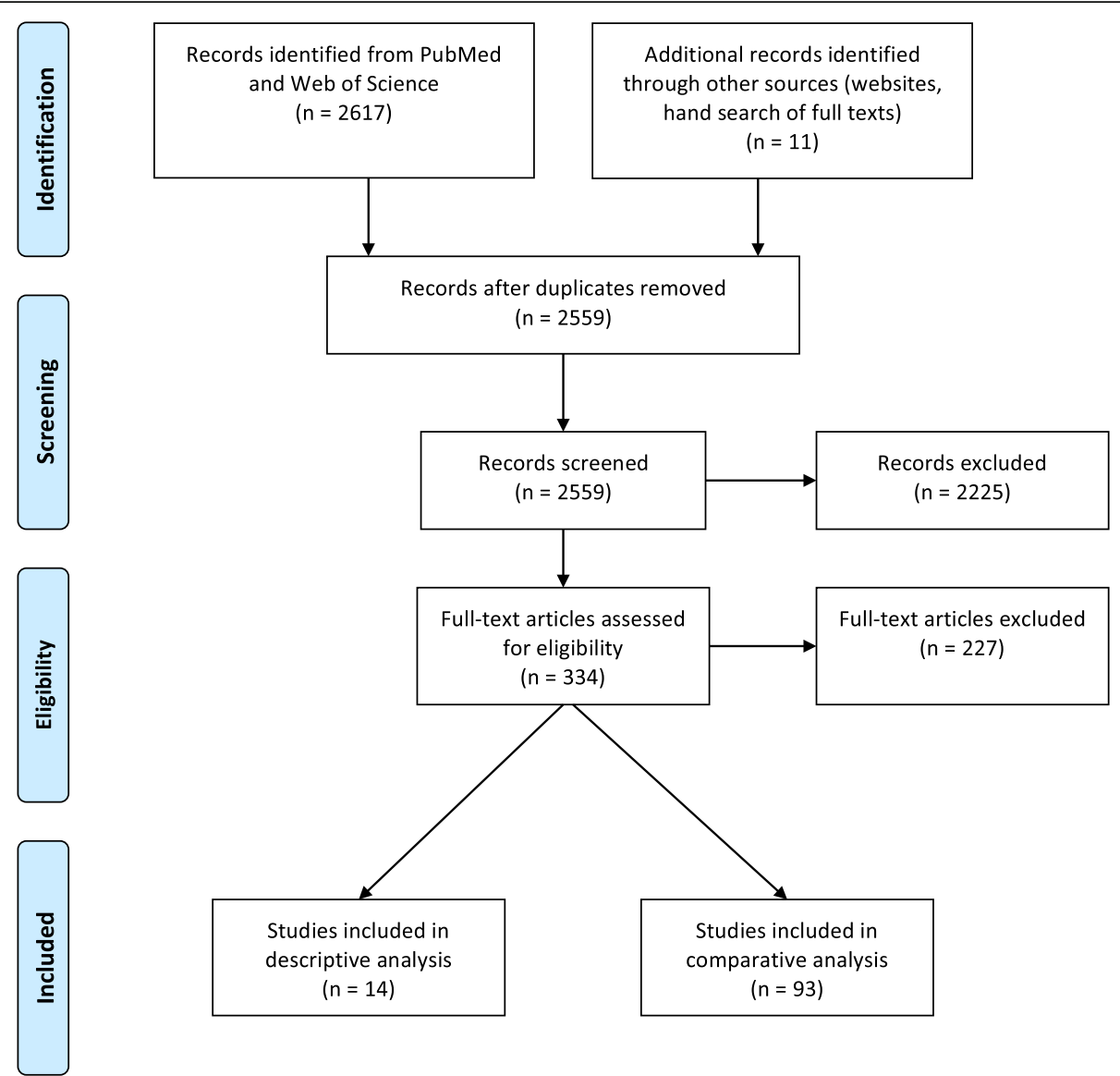

Fig. 1 PRISMA flow diagram of the study screening and selection process

\section{Selection and retrieval process}

Based upon selection criteria, two researchers (NM, $\mathrm{BC}$ ) independently evaluated each title and abstract. Every abstract was marked as selected/ not selected/ unclear in an Excel sheet. In case of disagreement on inclusion and exclusion, as well as when a paper fell into the "unclear" category, a third person (VL) took a decision. After review, 324 titles were chosen for full text review by the same researchers. Full texts were reviewed to ensure the publication met the inclusion criteria. Altogether 97 full texts were selected. After this, the references of the selected full texts were hand searched, and an additional 10 publications were included, as they met the inclusion criteria. All chosen full texts were located through university libraries or by contacting the authors directly.

\section{Data extraction}

The data was extracted in an Excel sheet (available upon request). Four trained researchers (NM, BC, SA, FS) participated in data extraction. After data from 10 papers was extracted, researchers met twice and discussed their strategies and concerns. This allowed controlling for differences in data extraction criteria and process between researchers (i.e. harmonization of this stage across individuals).

\section{Quality assessment}

Quality of the studies was assessed using nine quality criteria derived from the Strengthening the Reporting of Observational Studies in Epidemiology (STROBE) and the Mixed Methods Appraisal Tool Version 2011 (MMAT-Version 2011) to assess each publication as part of the data extraction: study question is well justified; study has clear objectives or hypothesis; study design is clear; participants are well described; the sample is representative of population of interest; sample size is adequate; the main outcome is clearly described; analyses are well described, and results are adjusted by confounders. A score from 0 to 9 was assigned to each study based on the nine quality criteria, and studies that fulfilled 0 to 3 criteria were labelled 'poor quality', 4 to 6 was considered 'average quality' and 7 to 9 criteria met indicated 'good quality'. 


\section{Data analysis}

In total, 107 full texts were included in the analyses. Fourteen publications that did not compare health care use of migrants with native populations were analysed separately from the 93 publications that did include a comparison to native populations.

Since there was significant heterogeneity in the themes, populations and results, a narrative synthesis instead of a meta-analysis was conducted. The main result was categorized into "lower utilization/access", "higher utilization/access" and "no significant difference" in comparison to native populations. Data analysis also included the description of recipient continents and countries, study design, type of migrant children, origin of migrants, sample size, main outcome, and control variables reported in all selected papers. It also includes a description of risk of bias assessment. Additionally, sub-group analyses were conducted by study topic for the following main themes: vaccines; mental health; hospital/emergency room (ER) use; oral health; general access/use; primary care; and other.

\section{Results}

\section{Description of comparative studies}

The 93 comparative studies, including 10.030.311 children, originated mostly from Europe (57\%) and North America (36\%) (Table 2, Fig. 2, Additional file 1: Table S1). The themes covered were general access or having a usual source of care (30\%), vaccines (20\%), mental health (18\%), hospital or emergency room use (16\%), oral health (14\%) and primary care use (13\%). Majority of the studies included large samples, with $40 \%$ having a sample size of over 10.000 . Some 35\% were nationally representative, and $47 \%$ utilized register data. Majority (77\%) of the studies adjusted for confounding variables, most commonly sex (48\%), age (47\%) and indicators of socioeconomic status $(16-23 \%)$.

The 93 studies reported in total 123 outcomes that could be categorised into "higher utilization/access", "lower utilization/access", "no significant difference" and "not reported". Half (50.4\%) of these outcomes indicated lower utilization of healthcare by migrants compared with non-migrants; $25.2 \%$ reported no difference, $17.9 \%$ reported higher use, and $6.5 \%$ did not report this outcome (Additional file 2: Table S2, Fig. 3). Analysing this by theme, the proportion of conclusions "lower utilization" was most common in the categories "general access to care", "primary care", "oral health", "vaccines" and "mental health", whereas in the use of hospital or ER services the most common conclusion was "higher utilization".

\section{Studies without a comparison group}

The 14 studies without comparison group (Additional file 2: Tables S2-S3) did not significantly differ in methodological characteristics, with the exception of smaller sample size, more frequent regional or local representativeness, and more frequent use of questionnaire as opposed to survey or register data. Two Australian studies without comparison group studied vaccines: the immunization coverage in immigrant children from East Africa [28] was found unknown or incomplete in $97 \%$. Another study reported on a schoolbased vaccination programme targeted for migrant youth, who had a low initial coverage $(30 \%$ for MMR and $18 \%$ for hepatitis B) [29]. Three studies reported on mental health, discovering high rates of unmet mental health needs in Chile [30] and US [31], but also high rates of mental health counselling received by unaccompanied Sudanese minors in the US [32]. Two studies analysed use of dental services [33, 34], finding suboptimal rates, and six studies reported on rates and diagnoses of primary care or hospital use [35-40].

The only study comparing migrants with the national population of the country of origin [41], analysed as part of the studies without comparison group since it did not include the national population, found lower rates of asthma but higher rates of infectious diseases among Japanese children living in Thailand than those living in Japan.

\section{Quality of studies}

Twelve studies (13\%) were considered of average quality and 82 (87\%) studies of good quality. No study was of poor quality. Of the quality criteria utilized, most frequently adjustment for confounders was missing (24 studies), followed by unclear study design (16 studies), inadequate sample size and unclear analysis (both 14 studies). Four out of twelve average-quality studies were national publications from Spain and Portugal; altogether nine were European, two North American and one was a South American publication.

\section{Sensitivity analysis with high quality studies}

Twelve studies of average quality were excluded to perform a sensitivity analysis with high quality studies only (available upon request). The results confirm findings of the complete analysis, with $50.0 \%$ of reported conclusions pointing towards less access or use of healthcare by migrants compared to non-migrants, and $20.2 \%$ concluding that access or use of healthcare was greater for migrants. 
Table 2 Description of the studies in the comparative analysis $(n=93)$

\begin{tabular}{|c|c|}
\hline & Number $(9$ \\
\hline \multicolumn{2}{|l|}{ Continent of receiving country } \\
\hline Europe & $54(58 \%)$ \\
\hline North America & $34(37 \%)$ \\
\hline Asia & $3(3 \%)$ \\
\hline Australia & $2(2 \%)$ \\
\hline \multicolumn{2}{|l|}{ Theme (combinations possible) } \\
\hline General access/having a usual source of care & $27(29 \%)$ \\
\hline Vaccines & 19 (22\%) \\
\hline Mental health & $16(17 \%)$ \\
\hline Hospital or ER use & $15(16 \%)$ \\
\hline Oral health & $14(15 \%)$ \\
\hline Primary care use & $12(13 \%)$ \\
\hline Other & $2(2 \%)$ \\
\hline \multicolumn{2}{|l|}{ Study population characteristics } \\
\hline \multicolumn{2}{|l|}{ Sample size } \\
\hline Sample size $<200$ & $8(9 \%)$ \\
\hline Sample size $200-10.000$ & $46(50 \%)$ \\
\hline Sample size $>10.000$ & $39(42 \%)$ \\
\hline \multicolumn{2}{|l|}{ Type of migrants } \\
\hline Not specified or mixed & 85 (91\%) \\
\hline Refugee only & $8(9 \%)$ \\
\hline Labour only & 0 \\
\hline \multicolumn{2}{|l|}{ Generation of migrants } \\
\hline Not specified or mixed & $13(14 \%)$ \\
\hline Only first-generation migrants & $16(17 \%)$ \\
\hline Only second-generation migrants & $64(69 \%)$ \\
\hline \multicolumn{2}{|l|}{ Age range } \\
\hline$<7$ years only & $14(15 \%)$ \\
\hline $12-18$ years only & $11(12 \%)$ \\
\hline Other or all children $0-18$ years & $68(73 \%)$ \\
\hline \multicolumn{2}{|l|}{ Origin of migrants } \\
\hline All or several countries & $37(40 \%)$ \\
\hline Hispanic & $6(6 \%)$ \\
\hline Asian & $2(2 \%)$ \\
\hline African & $1(1 \%)$ \\
\hline Non-Western/Less developed countries & $3(3 \%)$ \\
\hline Western countries & $1(1 \%)$ \\
\hline Turkey & $1(1 \%)$ \\
\hline Chile & $1(1 \%)$ \\
\hline North Korea & $1(1 \%)$ \\
\hline Not specified & $41(44 \%)$ \\
\hline
\end{tabular}

Table 2 Description of the studies in the comparative analysis $(n=93)$ (Continued)

\begin{tabular}{ll}
\hline & Number (\%) \\
\hline Methodological characteristics & \\
Study design & $76(82 \%)$ \\
Cross-sectional & $17(18 \%)$ \\
Longitudinal (prospective, retrospective) & \\
Study representativeness & $60(65 \%)$ \\
Regional & $33(35 \%)$ \\
National & \\
Data source (combinations possible) & $44(47 \%)$ \\
Register or other routine data & $29(31 \%)$ \\
National survey & $26(28 \%)$ \\
Questionnaire to a targeted study population & $7(8 \%)$ \\
Other & \\
Type of source (combinations possible) & $39(42 \%)$ \\
Register or other routine data & $36(39 \%)$ \\
Parent-report & $13(14 \%)$ \\
Self-report & $7(8 \%)$ \\
Other (e.g. blood sample) & $6(6 \%)$ \\
Confounding variables adjusted for (combinations possible) & $5(5 \%)$ \\
Sex & $24(26 \%)$ \\
Age & \\
Educathention of parents & $44(47 \%)$ \\
Need indicators (health status) & $22(24 \%)$ \\
\hline
\end{tabular}

\section{Discussion}

Main findings

This systematic review identified 107 studies reporting on healthcare use of migrant children, published from 2006 to 2016. To the best of our knowledge, it is the first attempt to systematize scientific knowledge on patterns of healthcare use among migrant children, a growing group with specific health and healthcare needs. The identified studies originated mostly from Europe and North America, with only $7 \%$ of studies coming from other regions. While these two regions host just over half of global international migrants [42], among children the distribution is different: three out of five child migrants live in Asia and Africa [10]. There is a clear lack of studies from these regions with large migrant populations. 


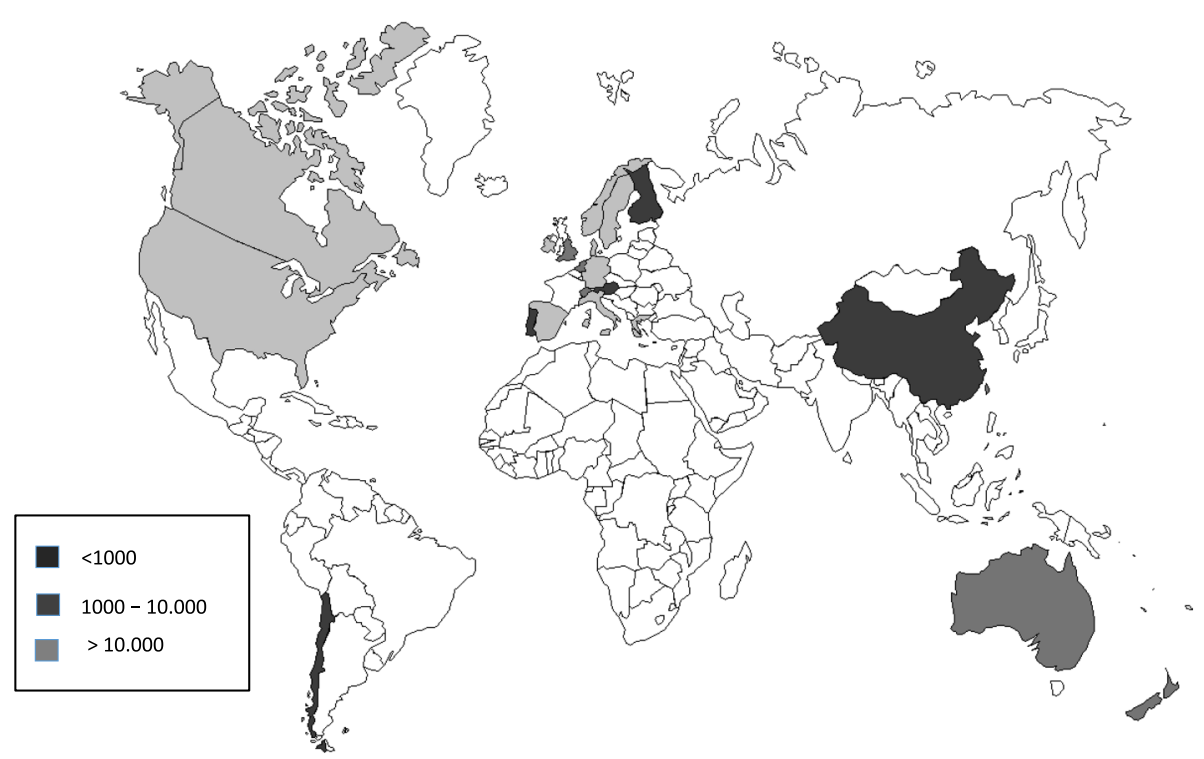

Fig. 2 Recipient countries of immigrants by sample size. Darkest grey indicates a sample size $<1000$ persons, medium grey $1000-10.000$ persons and lightest grey $>10.000$ persons

Methodologically the studies appear strong, with $87 \%$ categorized as meeting good quality criteria. Most studies had large sample sizes, one third of them were nationally representative, and a large majority adjusted for important confounding variables. However, majority of studies did not adjust for socioeconomic status, which could be problematic. Even fewer studies adjusted for indicators of need, such as health status, which should be considered when interpreting the results: migrant and native children may have differing healthcare needs, leading to different utilization patterns.

The studies focused on a few main themes, such as vaccinations, and oral and mental health, exploring both primary and specialized care use. Studies from the US frequently assessed existence of a usual source of care. Besides vaccinations and dental check-ups, no other aspects of preventive care or health promotion were studied. This is particularly noteworthy, since some

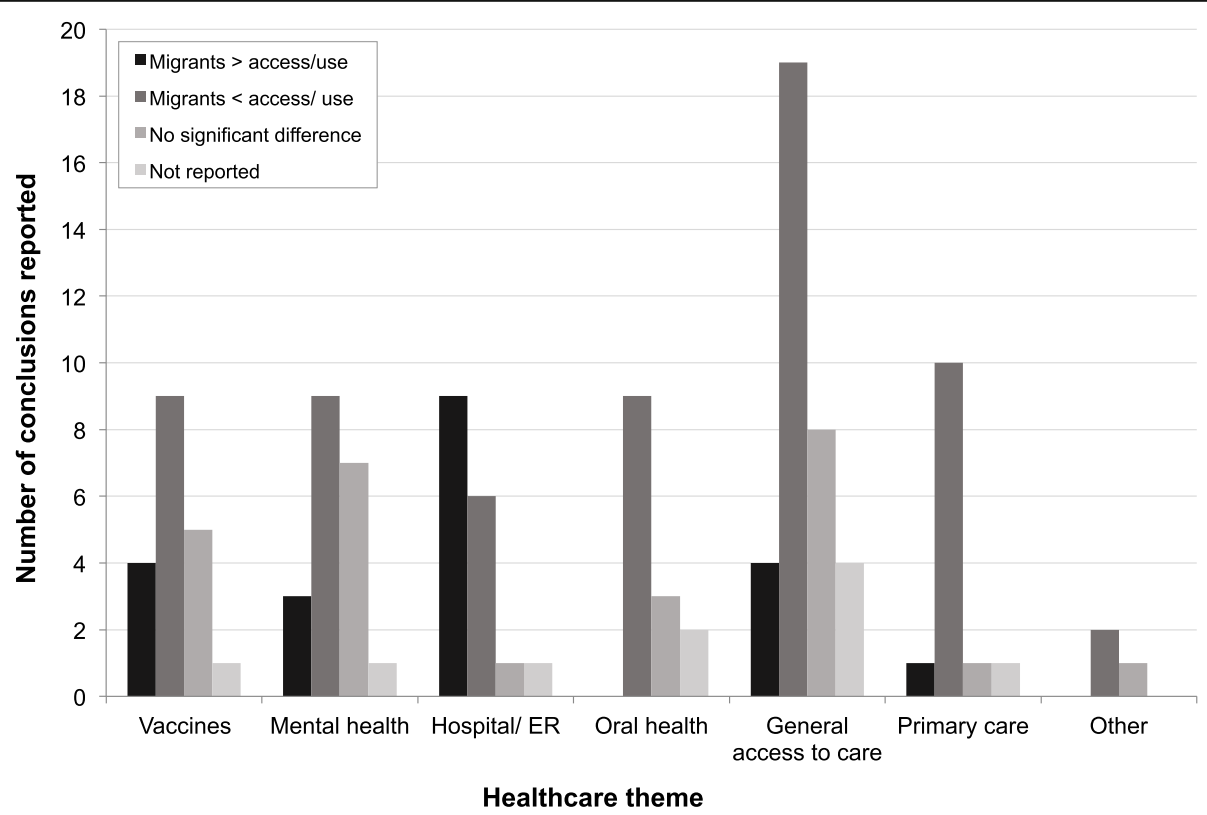

Fig. 3 Main conclusions of studies by healthcare theme 
migrant children in Europe have higher rates of risk factors such as obesity and physical inactivity than native children, which highlights the importance of health promotion in these groups [18]. Among migrant women, attendance to prenatal check-ups has been studied extensively and found generally to be lower than in native populations [16], and therefore preventive care use merits attention among migrant children as well.

Only $9 \%$ (8 studies) of the identified studies focused on refugees, and three additional studies included refugees. One of these studies was carried out in Asia [43], one in Australia [44], three in North America [37, 45, 46] and six in Europe [47-52]. In total, four studies found higher use of health services among refugees, four found lower service use and three found either no difference or they did not compare. As refugee children are a very specific and growing group [10], and findings regarding health service use among other type of migrants may not be applicable to them, the low number of studies on refugees brings to question what is really known about health service use of this particular group of children.

When analysing the main results by healthcare theme, the most striking difference is the relatively frequent finding of "higher use or access" in the category hospital and emergency room services. Majority of the studies that found higher use in this category originated from Europe [53-59], while two studies originated from North America [45, 60]. Two of the studies included refugees only, and three examined risk of hospitalization among children with type 1 diabetes $[54,55,57]$. A Swiss study found that migrants were overrepresented at the paediatric intensive care unit [59]. Therefore, several of these studies appear to indicate delayed care or problems in accessing routine treatment, rather than overuse.

\section{Possible reasons to reduced utilization and access}

Cultural norms, explanatory models of disease, lack of safety networks, language barriers and economic and social adversity all interplay in migrants' decision to seek and use health services [61]. The reasons for differing use of health services among migrant children could be categorized into family-related (such as fear, stigma, lack of trust, financial difficulties, problems in navigating new healthcare systems, lack of awareness of rights); those related to health professionals (communication problems, misconceptions, cultural barriers), and structural problems related to healthcare systems (lack of entitlement to care or restrictions to use, problems in physical access) [62].

These factors affect migrant families of different characteristics to varying degrees: Among migrants with undocumented immigration status, lack of awareness of their rights and functioning of health care systems, fear, and economic reasons may be the most important [63]. For refugees and asylum seekers, barriers to care are often related to legal entitlement, but organizational barriers and lack of provider expertise also influence their access to care [64]. Other barriers identified as important for labour-migrants in particular include lack of health insurance, lack of awareness about occupational health and safety regulations, and documentation status [62]. Several other issues have also been identified as influencing access among migrants: physically moving from one place to another, thereby discontinuing any on-going treatment or vaccine series; lack of coordination among the health authorities inside and between countries; and lack of resources in the hosting countries [24].

A potential factor influencing access of all migrants and ethnic minorities are health care professionals' skills and attitudes. A systematic review identified three main components of this barrier: biases, stereotypes and prejudices; language and communication barriers, and cultural misunderstandings [65]. Another systematic review concludes that this type of implicit bias is likely to influence clinical decisions [66].

Finally, different use of health services may also result from different needs. While this is likely not true for lower vaccination rates or lower use of dental care, it may explain to some extent lower use of other services, where the need appears to be less than in native populations. The 'healthy migrant effect' has been observed in rates of asthma, some mental problems and risky health behaviours, which all appear to be lower than among native populations $[13,67]$.

\section{Comparison to other studies}

Another systematic review on adult migrants' health service use, limited to use of somatic services and the European region [23], found more varying results than our review. Use of preventive services such as mammography screening was lower, whereas use of general practitioners' services and rate of hospitalizations was higher. A recent systematic review focused on the use of emergency department services in Europe found higher and sometimes inappropriate use among migrants [68]. One explanation proposed by the authors is difficulties in accessing more appropriate sources of health care.

Also in line with our findings, a systematic review on vaccination coverage of rural-urban migrant children found a lower rate among migrants than the general population [69]. Similarly, a systematic review on vaccine coverage of migrant and refugee adults in Europe found lower coverage than among native populations [24]. 


\section{Strengths and limitations}

To our knowledge, this is the first effort to systematize published research on the use of health services of international migrant children. We used a broad search strategy and found a large number of studies, reporting on more than 10 million children.

However, the study has certain limitations that should be considered. The identified studies were heterogeneous, which makes interpretation of the results more challenging, and also prevented us from carrying out a meta-analysis. Unfortunately, information on countries of origin of the migrants was not available for many studies, and it was not possible to analyse studies by subgroups based on country of origin. Also analyses by type of migrants were not possible because this information was frequently lacking, and number of studies in each group was small. Our review was limited to literature published between 2006 and 2016 and to two databases, and therefore possibly relevant literature could have been missed. Findings published in reports or in languages other than the ones included could also be relevant, and were not included in this study. Most studies originated from Europe and North America, and therefore we cannot draw firm conclusions on migrant children settled in other regions of the world. Some studies were not originally designed to address research questions about migrants or not focused on children, which could also be considered a limitation.

Additionally, it should be noted that the comparison between migrants and native populations does not take into account suboptimal access of native children [70-72]. Nevertheless, in a review the comparison to native populations is the clearest method to point out inequalities in service use between these two groups, even though both may have problems in accessing health care. Further, this study only addressed health service use in the post-migratory situation, leaving out many significant variables that affect why, how and when they migrated, as well as what patterns of access to healthcare existed in their countries of origin. By systematizing several studies, this review overlooks the unique characteristics of individual studies and contexts. To include these complexities would be very hard to disentangle in a single systematic review, and therefore this study can be considered a baseline for further studies, and as such aims to analyse the general tendencies of patterns of use of healthcare among migrant children. International migration should be studied at the local, national, regional and global scales, as this phenomenon responds to complex and dynamic processes of globalization, international labour stratification, poverty and conflict. This paper is unable to mirror all these factors, but they could be studied using different methodologies than a systematic review.

\section{Implications}

Migrant children have reduced use of many types of health services. According to our findings, only the use of emergency and hospital services was found to be higher than native populations, which appears to indicate problems in accessing care at earlier stages or more appropriate places.

Targeted policies could help overcome these barriers in access to healthcare. For example, improving health literacy seems to have the potential to empower patients and reduce health inequalities, and there are effective interventions to improve health literacy among migrants [73]. Regarding health providers, some of the identified barriers could be ameliorated with system changes, such as utilization of interpreters, whereas others would require specific interventions such as cultural competence education for health professionals [74]. Recently, interventions to improve immigrant health were reviewed, and many specific policies for adult migrants were identified. However, only $11 \%$ of the results were policies directed to children [75]. There appears to be a need to develop and document policies to improve access to care for child migrants.

Future research should extend beyond Europe and North America to the regions with most child migrants: Asia, Africa and South America. Moreover, while the identified studies were large and used reliable methods, the majority did not control for measures of socioeconomic status, and few were able to control for indicators of need, such as health status. It is important to develop study methodologies that can better control for confounding factors, and more precisely measure the impact of migration on service use. Since migrant groups are different in terms of their health care needs, reasons for migration, region of origin and time since arrival should be documented more carefully both in registers and in studies, to identify and analyse groups that have a particularly high risk of underuse of services. Finally, the reasons and mechanisms for foregone and delayed care should be also evaluated in epidemiological studies.

\section{Conclusion}

Children of international migrants use most types of healthcare services less than local children: they are less likely to have a usual health service provider, to use preventive services, primary and dental care, and some specialised health services. Considering the risk that international migration presents to health, these findings warrant action both to ensure equitable access to health services, and to safeguard the right to health for all children. 


\section{Additional files}

Additional file 1: Table S1. Results of the studies with comparison group $(n=93)$. (XLSX $50 \mathrm{~kb})$

Additional file 2: Table S2. Healthcare use by migrant children: number of main conclusions reported by theme. Table S3. Description of the studies without comparison group $(n=14)$. Table S4. Results of the studies without comparison group $(n=14)$. (DOCX $75 \mathrm{~kb})$

\section{Acknowledgements}

We are grateful to Ms. Anita Jasmén S., Biomedical Library Coordinator, of the Faculty of Medicine, Clínica Alemana - Universidad del Desarrollo, and Ms. Cecilia Pacheco V., Chief of the Medical Information Centre, Iberoamerican Cochrane Group of Clinical Documentation, Clínica Alemana de Santiago, who helped design and carry out the database searches.

\section{Funding}

This research was supported by: (i) Fondecyt Project 11130042; (ii) Universidad del Desarrollo Inter-Faculty Funds; (iii) Jalmari and Rauha Ahokas Foundation.

\section{Availability of data and materials}

The datasets used and/ analysed during the current study are available from the corresponding author on reasonable request.

\section{Authors' contributions}

NM and BC conceptualized and designed the study, participated in the study selection, data extraction and data analysis, and wrote the first and subsequent drafts of the manuscript. VL conceptualized and designed the study, participated in the study selection, and reviewed and revised all versions of the manuscript. EU carried out the data analyses, produced the graphics, and reviewed and revised all versions of the manuscript. SA and FS participated in the data extraction and reviewed and revised the manuscript. All authors approved the final manuscript as submitted and agree to be accountable for all aspects of the work.

\section{Ethics approval and consent to participate} Not applicable.

\section{Competing interests}

The authors declare that they have no competing interests.

\section{Publisher's Note}

Springer Nature remains neutral with regard to jurisdictional claims in published maps and institutional affiliations.

\begin{abstract}
Author details
${ }^{1}$ Social Studies in Health Research Programme, Instituto de Ciencias e Innovación en Medicina (ICIM), Facultad de Medicina, Clínica Alemana Universidad del Desarrollo, Av. Las Condes 12461, Las Condes, Santiago, Chile. ${ }^{2}$ Department of Health Sciences, University of York, York, England. ${ }^{3}$ Department of Psychiatry, Helsinki University Hospital and University of Helsinki, Helsinki, Finland. ${ }^{4}$ Centre for Interdisciplinary and Intercultural Inquiry, Health Humanities, University College London, London, UK.
\end{abstract}

Received: 18 October 2017 Accepted: 6 May 2018

Published online: 16 May 2018

\section{References}

1. IOM: World Migration Report 2015. Migrants and Cities: New Partnerships to Manage Mobility. Geneva: International Organization for Migration; 2015

2. Castaneda H, Holmes SM, Madrigal DS, Young ME, Beyeler N, Quesada J. Immigration as a social determinant of health. Annu Rev Public Health. 2015;36:375-92.

3. Gushulak BD, MacPherson DW. The basic principles of migration health: population mobility and gaps in disease prevalence. Emerg Themes Epidemiol. 2006;3:3.
4. Gushulak B, Weekers J, Macpherson D. Migrants and emerging public health issues in a globalized world: threats, risks and challenges, an evidencebased framework. Emerg Health Threats J. 2009;2:e10.

5. Macpherson DW, Gushulak BD, Macdonald L. Health and foreign policy: influences of migration and population mobility. Bull World Health Organ. 2007:85:200-6.

6. Marmot, M.: Fair society, healthy lives. The marmot review. Strategic review of health inequalities in England post-2010. 2010.

7. United Nations. Department of Economic and Social Affairs, Population Division. International Migration Report 2017: Highlights (ST/ESA/SER.A/404). 2017. http://www.un.org/en/development/desa/population/migration/ publications/migrationreport/docs/MigrationReport2017_Highlights.pdf

8. UN General Assembly, New York Declaration for Refugees and Migrants resolution / adopted by the General Assembly, 3 October 2016, A/RES/71/1, available at: http://www.refworld.org/docid/57ceb74a4.html. Accessed 9 May 2018.

9. Carballo M, Hargreaves S, Gudumac I, Maclean EC. Evolving migrant crisis in Europe: implications for health systems. Lancet Glob Health. 2017;5:e252-3.

10. UNICEF. Uprooted - the growing crisis for refugee and migrant children. New York: United Nations Children's Fund (UNICEF); 2016.

11. United Nations: Convention on the rights of the child, article 24. 1989.

12. Giannakopoulos G, Anagnostopoulos DC. Child health, the refugees crisis, and economic recession in Greece. Lancet. 2016;387:1271.

13. Mendoza FS. Health disparities and children in immigrant families: a research agenda. Pediatrics. 2009;124:S187-95.

14. UNITAR: Migration and youth: overcoming health challenges. In Migration and development (United Nations Institute for Training and Research ed. New York; 2011

15. Fazel M, Reed RV, Panter-Brick C, Stein A. Mental health of displaced and refugee children resettled in high-income countries: risk and protective factors. Lancet. 2012;379:266-82.

16. Heaman M, Bayrampour H, Kingston D, Blondel B, Gissler M, Roth C, Alexander S, Gagnon A. Migrant women's utilization of prenatal care: a systematic review. Matern Child Health J. 2013;17:816-36.

17. Jaeger FN, Hossain M, Kiss L, Zimmerman C. The health of migrant children in Switzerland. Int J Public Health. 2012:57:659-71.

18. Gualdi-Russo E, Zaccagni L, Manzon VS, Masotti S, Rinaldo N, Khyatti M. Obesity and physical activity in children of immigrants. Eur J Pub Health. 2014;24(Suppl 1):40-6.

19. Stevens GW, Vollebergh WA. Mental health in migrant children. J Child Psychol Psychiatry. 2008;49:276-94.

20. Belhadj Kouider E, Koglin U, Petermann F. Emotional and behavioral problems in migrant children and adolescents in Europe: a systematic review. Eur Child Adolesc Psychiatry. 2014;23:373-91.

21. Fazel M, Karunakara U, Newnham EA. Detention, denial, and death: migration hazards for refugee children. Lancet Glob Health. 2014;2:e313-4

22. Almeida LM, Caldas J, Ayres-de-Campos D, Salcedo-Barrientos D, Dias S. Maternal healthcare in migrants: a systematic review. Matern Child Health J. 2013:17:1346-54.

23. Norredam M, Nielsen SS, Krasnik A. Migrants' utilization of somatic healthcare services in Europe-a systematic review. Eur J Pub Health. 2010; 20:555-63.

24. Mipatrini D, Stefanelli $P$, Severoni S, Rezza G. Vaccinations in migrants and refugees: a challenge for European health systems. A systematic review of current scientific evidence. Pathog Glob Health. 2017;111:59-68.

25. Gulati S, Watt L, Shaw N, Sung L, Poureslami IM, Klaassen R, Dix D, Klassen AF. Communication and language challenges experienced by Chinese and south Asian immigrant parents of children with cancer in Canada: implications for health services delivery. Pediatr Blood Cancer. 2012;58:572-8.

26. Blewett LA, Johnson PJ, Mach AL. Immigrant children's access to health care: differences by global region of birth. J Health Care Poor Underserved. 2010;21:13-31.

27. Cabieses B, Bird P. Glossary of access to health care and related concepts for low- and middle-income countries (LMICS): a critical review of international literature. Int J Health Serv. 2014;44:845-61.

28. Paxton GA, Rice J, Davie G, Carapetis JR, Skull SA. East African immigrant children in Australia have poor immunisation coverage. J Paediatr Child Health. 2011:47:888-92.

29. Milne B, Raman S, Thomas P, Shah S. Immunisation of refugee and migrant young people: can schools do the job? Aust N Z J Public Health. 2006;30:526-8. 
30. Rojas G, Fritsch R, Castro A, Guajardo V, Torres P, Diaz B. Mental disorders among immigrants in Chile. Revista Medica De Chile. 2011;139:1298-304.

31. Toppelberg CO, Hollinshead MO, Collins BA, Nieto-Castanon A. Crosssectional study of unmet mental health need in 5- to 7-year old Latino children in the United States: do teachers and parents make a difference in service utilization? Sch Ment Health. 2013:5:59-69.

32. Geltman PL, Grant-Knight W, Ellis H, Landgraf JM. The "lost boys" of Sudan: use of health services and functional health outcomes of unaccompanied refugee minors resettled in the U.S. J Immigr Minor Health. 2008;10:389-96.

33. Nahouraii H, Wasserman M, Bender DE, Rozier RG. Social support and dental utilization among children of Latina immigrants. J Health Care Poor Underserved. 2008;19:428-41.

34. Quandt SA, Clark HM, Rao P, Arcury TA. Oral health of children and adults in Latino migrant and seasonal farmworker families. J Immigr Minor Health. 2007:9:229-35

35. del Rosario CR, Diaz SN, de Carlos PG, Palmero IR, Mahtani VM, Rodriguez MAH, Rodriguez LM, Martinez CO, Moreno SD, Bilbao JLA. Health care for African immigrants arriving in the Canary Islands a descriptive study. Emergencias. 2008;20:411-8.

36. Sabbatani S, Baldi E, Manfredi R. Causes of hospitalization among extraEuropean Union children in a large hospital of northern Italy, in a five-year observation period. Braz J Infect Dis. 2007;11:6-8

37. Watts DJ, Friedman JF, Vivier PM, Tompkins CE, Alario AJ. Immunization status of refugee children after resettlement. Med Health R I. 2011;94:290-3.

38. Thomas P, Milne B, Raman S, Shah S. Refugee youth-immunisation status and GP attendance. Aust Fam Physician. 2007;36:568-70.

39. Yun K, Chesnokova A, Shults J, Pinto A, Rubin DM. Use of preventive dental care among medicaid-enrolled, school-aged US children in immigrant and nonimmigrant families: trends in Pennsylvania from 2005 through 2010. Am J Public Health. 2014;104:2400-8.

40. Beiki O, Karimi N, Mohammadi R. Parental educational level and injury incidence and mortality among foreign-born children: a cohort study with 46 years follow-up. J Inj Violence Res. 2014;6:37-43.

41. Sakai R, Wongkhomthong SA, Marui E. Disease patterns of outpatient visits by Japanese expatriate children in Thailand. Acta Paediatr. 2009;98:573-8.

42. UN. International Migration Report 2015: Highlights (ST/ESA/SER.A/375). New York: United Nations, Department of Economic and Social Affairs, Population Division; 2016.

43. Chung HJ, Han SH, Kim H, Finkelstein JL. Childhood immunizations in China: disparities in health care access in children born to North Korean refugees. BMC Int Health Hum Rights. 2016;16:13.

44. Enticott JC, Cheng IH, Russell G, Szwarc J, Braitberg G, Peek A, Meadows G. Emergency department mental health presentations by people born in refugee source countries: an epidemiological logistic regression study in a Medicare local region in Australia. Aust J Prim Health. 2015;21:286-92.

45. Kiss V, Pim C, Hemmelgarn BR, Quan H. Building knowledge about health services utilization by refugees. J Immigr Minor Health. 2013;15:57-67.

46. Guttmann A, Manuel D, Stukel TA, Desmeules M, Cernat G, Glazier RH. Immunization coverage among young children of urban immigrant mothers: findings from a universal health care system. Ambul Pediatr. 2008;8:205-9.

47. Alkahtani S, Cherrill J, Millward C, Grayson K, Hilliam R, Sammons H, Choonara I. Access to medicines by child refugees in the east midlands region of England: a cross-sectional study. BMJ Open. 2014;4:e006421.

48. Ramel B, Taljemark J, Lindgren A, Johansson BA. Overrepresentation of unaccompanied refugee minors in inpatient psychiatric care. Spring. 2015:4:131.

49. Vaage AB, Garlov I, Hauff E, Thomsen PH. Psychiatric symptoms and service utilization among refugee children referred to a child psychiatry department: a retrospective comparative case note study. Transcult Psychiatry. 2007;44:440-58

50. Bean T, Eurelings-Bontekoe E, Mooijaart A, Spinhoven P. Factors associated with mental health service need and utilization among unaccompanied refugee adolescents. Admin Pol Ment Health. 2006;33:342-55.

51. Dyhr L, Andersen JS, Engholm G. The pattern of contact with general practice and casualty departments of immigrants and non-immigrants in Copenhagen, Denmark. Dan Med Bull. 2007:54:226-9.

52. Skokauskas N, Dunne M, Gallogly A, Clark C. Ethnic minority populations and child psychiatry services: an Irish study. Child Youth Serv Rev. 2010; 32:1242-5.

53. Arizaleta LH, Rodriguez JP, Cid MM, Piqueras OM. Impact of immigration on hospital care: utilization, case-mix, and economic effects. Gac Sanit. 2009;23: 208-15.
54. Bächle C, Haastert B, Holl RW, Beyer P, Grabert M, Giani G, Icks A. Inpatient and outpatient health care utilization of children and adolescents with type 1 diabetes before and after introduction of DRGs. Exp Clin Endocrinol Diabetes. 2010;118:644-8.

55. Icks A, Rosenbauer J, Strassburger K, Grabert M, Giani G, Holl RW. Persistent social disparities in the risk of hospital admission of paediatric diabetic patients in Germany-prospective data from 1277 diabetic children and adolescents. Diabet Med. 2007;24:440-2.

56. Ballotari P, D'Angelo S, Bonvicini L, Broccoli S, Caranci N, Candela S, Giorgi Rossi P. Effects of immigrant status on emergency room (ER) utilisation by children under age one: a population-based study in the province of Reggio Emilia (Italy). BMC Health Serv Res. 2013;13:458.

57. Karges B, Rosenbauer J, Holterhus PM, Beyer P, Seithe H, Vogel C, Bockmann A, Peters D, Muther S, Neu A, Holl RW. Hospital admission for diabetic ketoacidosis or severe hypoglycemia in 31,330 young patients with type 1 diabetes. Eur J Endocrinol. 2015;173:341-50.

58. Sandvik H, Hunskaar S, Diaz E. Immigrants' use of emergency primary health care in Norway: a registry-based observational study. BMC Health Serv Res. 2012;12:308.

59. Tritschler T, Sennhauser F, Frey B. Are immigrant children admitted to intensive care at increased risk? Swiss Med Wkly. 2011;141:w13190.

60. Sanders LM, Thompson VT, Wilkinson JD. Caregiver health literacy and the use of child health services. Pediatrics. 2007;119:e86-92.

61. Ahmed S, Shommu NS, Rumana N, Barron GR, Wicklum S, Turin TC. Barriers to access of primary healthcare by immigrant populations in Canada: a literature review. J Immigr Minor Health. 2016;18:1522-40.

62. Simon J, Kiss N, Łaszewska A, Mayer S. Public health aspects of migrant health: a review of the evidence on health status for labour migrants in the European region. In: WHO health evidence network synthesis reports. Copenhagen: WHO Regional Office for Europe; 2015.

63. Woodward A, Howard N, Wolffers I. Health and access to care for undocumented migrants living in the European Union: a scoping review. Health Policy Plan. 2014;29:818-30.

64. Bradby H, Humphris R, Newall D, Phillimore J. Public health aspects of migrant health: a review of the evidence on health status for refugees and asylum seekers in the European region. In: WHO health evidence network synthesis reports. Copenhagen: WHO Regional Office for Europe; 2015.

65. Drewniak D, Krones T, Wild V. Do attitudes and behavior of health care professionals exacerbate health care disparities among immigrant and ethnic minority groups? An integrative literature review. Int J Nurs Stud. 2017;70:89-98.

66. FitzGerald C, Hurst S. Implicit bias in healthcare professionals: a systematic review. BMC Med Ethics. 2017;18:19.

67. Cabieses B, Uphoff E, Pinart M, Anto JM, Wright J. A systematic review on the development of asthma and allergic diseases in relation to international immigration: the leading role of the environment confirmed. PLoS One. 2014;9:e105347

68. Crede SH, Such E, Mason S. International migrants' use of emergency departments in Europe compared with non-migrants' use: a systematic review. Eur J Pub Health. 2017;28(1):61-73.

69. Awoh $A B$, Plugge $E$. Immunisation coverage in rural-urban migrant children in low and middle-income countries (LMICS): a systematic review and metaanalysis. J Epidemiol Community Health. 2016;70:305-11.

70. Mayor S. Children still wait too long to get mental healthcare, finds review. BMJ. 2017;359:j4993

71. Spencer DL, McManus M, Call KT, Turner J, Harwood C, White P, Alarcon G. Health care coverage and access among children, adolescents, and young adults, 2010-2016: implications for future health reforms. J Adolesc Health. 2018;

72. Leininger $\mathrm{L}$, Levy $\mathrm{H}$. Child health and access to medical care. Future Child. 2015;25:65-90

73. Fernández-Gutiérrez M, Bas-Sarmiento P, Albar-Marín MJ, Paloma-Castro O, Romero-Sánchez JM: Health literacy interventions for immigrant populations: a systematic review. Int Nurs Rev: 2017.

74. Horvat L, Horey D, Romios P, Kis-Rigo J. Cultural competence education for health professionals. Cochrane Database Syst Rev. 2014;(5):CD009405. https://doi.org/10.1002/14651858.CD009405.pub2

75. Diaz E, Ortiz-Barreda G, Ben-Shlomo Y, Holdsworth M, Salami B, Rammohan A, Chung RY-N, Padmadas SS, Krafft T. Interventions to improve immigrant health. A scoping review. Eur J Public Health. 2017;27:433-9. 